\title{
Mineração em territórios quilombolas: notas sobre uma consulta prévia em Trombetas, Oriximiná-PA
}

\section{Mining in quilombola lands: notes on prior consultations in Trombetas, Oriximiná-PA}

Erika Beser - Doutora pelo Programa de Pós-Graduação Sociedade, Natureza e Desenvolvimento (PPGSND) na Universidade Federal do Oeste do Pará (UFOPA). Antropóloga no Instituto Nacional de Colonização e Reforma Agrária (INCRA/MT). E-mail: erika_giuliane@yahoo.com.br

Luciana Gonçalves de Carvalho - Doutora pelo Programa de Pós-Graduação em Sociologia e Antropologia (PPGSA) na Universidade Federal do Rio de Janeiro (UFRJ). Professora na Universidade Federal do Oeste do Pará (UFOPA).E-mail: luciana.gdcarvalho@gmail.com

\section{Resumo}

O objetivo deste artigo é contextualizar a aplicação do instrumento jurídico da consulta prévia no âmbito de um projeto de mineração em áreas protegidas e pleiteadas por comunidades quilombolas nas margens do rio Trombetas, em OriximináPA. A pesquisa baseia-se em fontes processuais e documentos acostados nos autos do Inquérito Civil que repercutiu na obrigação de realização da referida consulta. Os resultados preliminares do estudo apontam a coexistência de entendimentos e expectativas distintas em torno da consulta prévia, por parte das comunidades e do Ministério Público Federal que obrigou a sua realização.

\section{Palavras-chave}

Consulta Prévia. Mineração. Território Quilombola. Unidades de Conservação.

\begin{abstract}
This article describes the process of prior consultation in the context of a mining project in protected areas claimed by Quilombola communities on the banks of the Trombetas River in Oriximiná, state of Pará, Brazil. Its research is based on the procedural sources and documents attached to the records of the Civil Inquest that led to this particular consultation. Its initial results point at different interpretations and expectations regarding this process by the communities involved in it, on the one hand, and, on the other, by the Federal Public Prosecutor's Office as the institution that called for its execution.
\end{abstract}

\section{Keywords}

Prior Consultations. Mining. Quilombola Lands. Conservation Units. 


\section{INTRODUÇÃO}

Há quatro décadas as 14 comunidades quilombolas que, atualmente, integram os territórios Alto Trombetas I e Alto Trombetas II, ${ }^{1}$ no município de Oriximiná-PA, convivem com duas Unidades de Conservação (UC) federais e a mineração de bauxita sobrepostas a áreas que elas ocupam desde o século XIX. Assim, embora se dediquem regularmente a atividades tradicionais de roça, caça, pesca e extração de gêneros florestais, (destacadamente castanha e copaíba) - as quais são restritas nas UC -, é notório que um número cada vez maior de moradores mantém relações de trabalho com a mineração, as quais se refletem em vínculos de dependência econômica, alianças políticas ocasionais ou duradouras, e também conflitos (ACEVEDO; CASTRO, 1993; WANDERLEY, 2008). Nesse sentido, é recorrente ouvir dos quilombolas, a respeito da mineradora e dos órgãos ambientais atuantes nos territórios, que "eles entram sem pedir licença".

O pessoal já está mais de olho aberto, muitos já tiveram mais estudo. Dos anos que nós morávamos aqui, meu pai não tinha estudo nenhum, não tinha nada, aí chegava aqui: "Olha, peguei a terra e dá licença que vamos fazer um trabalho aqui”. [...] Meu pai, o que qualquer um lhe dissesse, ele aceitava (CUMBUCA NORTE, 2016, p. 180).

Contudo, como o depoimento acima demonstra, o acesso à informação e a crescente consciência de direitos têm alimentado mudanças de atitudes entre os quilombolas. Foi assim que, em caráter inédito, em 2012, representantes de dois territórios quilombolas do Alto Trombetas denunciaram ao Ministério Público Federal (MFP) em Santarém-PA que a empresa Mineração Rio do Norte (MRN) vinha realizando atividades em áreas ocupadas pelas comunidades, sem que houvesse dialogado com elas sobre suas pretensões, conforme relato abaixo:

A mineração é o seguinte: hoje só está tendo essa conversa porque 27 de novembro de 2012 nós estivemos em Brasília para fazer uma denúncia dela, da Mineração. Eles já [tinham] passado por cima de nós, [...] eles não tiveram consideração de chegar com as comunidades e dizer assim:

\footnotetext{
O Território Quilombola (TQ) Alto Trombetas I abrange as comunidades Mãe Cué, Tapagem, Sagrado Coração de Jesus, Paraná do Abuí, Santo Antônio do Abuizinho e Abuí, e é representado pela Associação Mãe Domingas. O TQ Alto Trombetas II abrange as comunidades Moura, Último Quilombo, Nova Esperança, Palhal, Juquiri Grande, Juquirizinho, Jamari e Curuçá, e é representado pela Associação das Comunidades Remanescentes de Quilombos do Alto Trombetas II (ACRQAT). Ambas as associações têm processos administrativos em curso na SR-30/Santarém no Instituto Nacional de Reforma Agrária (Incra) visando a delimitação e titulação dos territórios que representam, sendo que o TQ Alto Trombetas I é parcialmente titulado pelo Instituto de Terras do Pará (Iterpa). A finalização desses processos, datados de 2004, tem sido dificultada e postergada, entre outros fatores, pela sobreposição com duas Unidades de Conservação (UC) federais: a Floresta Nacional (Flona) Saracá-Taquera e a Reserva Biológica (Rebio) do Trombetas.
} 
"Pessoal, nós vamos mexer aqui". Não. Eles dizem que até hoje eles se arrependem de ter passado pelo rio. Porque nós só descobrimos [as atividades que a mineradora vinha realizando] porque eles passaram pelo rio, porque, quando nós vimos o excesso de lancha, a gente começou a desconfiar o que estava acontecendo (CUMBUCA NORTE, 2016, p. 217).

Diante da denúncia, o MPF abriu o Inquérito Civil (IC) $\mathrm{n}^{\circ}$ 1.23.002.000480/2012-81. No âmbito desse procedimento, enquanto procedeu à apuração dos fatos, o MPF recomendou a suspensão das autorizações previamente concedidas pelo Instituto Brasileiro do Meio Ambiente e dos Recursos Naturais Renováveis (Ibama) à MRN e determinou a realização da consulta prévia, livre e informada às comunidades, conforme preconiza a Convenção n⿳0 169 sobre os Povos Indígenas e Tribais (C169) da Organização Internacional do Trabalho (OIT). De acordo com a interpretação da convenção para a realidade brasileira, as comunidades remanescentes de quilombos têm direito de definir as próprias prioridades no processo de desenvolvimento econômico, social e cultural, bem como de participar dos processos decisórios que as afetem, mesmo em se tratando de terras ou recursos de propriedade da União, conforme pactuado no Art. 15:

Em caso de pertencer ao Estado a propriedade dos minérios ou dos recursos do subsolo, ou de ter direitos sobre outros recursos, existentes nas terras, os governos deverão estabelecer ou manter procedimentos com vistas a consultar os povos interessados, a fim de se determinar se os interesses desses povos seriam prejudicados, e em que medida, antes de se empreender ou autorizar qualquer programa de prospecção ou exploração dos recursos existentes nas suas terras. Os povos interessados deverão participar sempre que for possível dos benefícios que essas atividades produzam, e receber indenização eqüitativa por qualquer dano que possam sofrer como resultado dessas atividades.

A referida consulta sucedeu-se, portanto, em meio a episódios conectados ao procedimento jurídico e dotados de alta carga moral-legal (OLIVEIRA, 2002), envolvendo um conjunto de atores sociais que exercem poderes distintos sobre os territórios quilombolas do Alto Trombetas. O processo padeceu de dificuldades incontestes no que diz respeito à garantia das condições para que a consulta fosse, efetivamente, prévia, livre e informada, transfigurando-se em um drama social (TURNER, 2008) marcado por dissidências internas e desavenças entre líderes quilombolas, além de desacordos com os órgãos envolvidos, conflitos com a empresa e divergências com o próprio MPF que buscou proteger o direito das comunidades.

Neste artigo, baseado principalmente em pesquisa de documentos acostados nos autos do inquérito - atas de reuniões, despachos, pareceres 
e recomendações, entre outros - e algumas entrevistas realizadas com líderes comunitários, busca-se compreender os sentidos dramáticos que a consulta assumiu perante os quilombolas. Para tanto, parte-se da hipótese de que o IC criou situações de reparação da invisibilidade jurídica (LEITE, 1996; OLIVEIRA, 2002) das comunidades, mas acentuou sua invisibilidade moral em uma série de atos que foram percebidos pelos sujeitos em questão como desconsideração, no sentido apontado por Oliveira (2002, p. 9):

A desconsideração como insulto moral, é caracterizada como um ato ou atitude que agride direitos de natureza ético-moral [...]. Diferentemente das agressões a direitos jurídicos-legais, o insulto moral não pode ser traduzido, de imediato, em evidências materiais.

O artigo compõe-se de duas partes, além desta introdução e de considerações finais: a primeira é dedicada à revisão de institutos que asseguram direitos às comunidades remanescentes de quilombos, destacadamente a Convenção $n^{\circ}$ 169; a segunda comenta e analisa o processo de consulta acerca da mineração na região de Trombetas. Partindo de excertos do IC e relatos de quilombolas, bem como da categoria analítica de drama social -formulada por Victor Turner (1996) para abordar o conflito como mecanismo imprescindível da dinâmica da vida social, especialmente em contextos críticos de mudança -, o artigo demonstra que a efetiva implementação do instituto da consulta é objeto de enfrentamentos agravados pela própria disparidade entre pontos de vista, percepções e expectativas de direitos por parte dos envolvidos. Por fim, revelando dinâmicas próprias do processo analisado, espera-se contribuir para os debates atuais sobre o instituto da consulta prévia, livre e informada no campo da Antropologia Jurídica e do Direito. ${ }^{2}$

\section{A CONVENÇÃO № 169 E O DIREITO À CONSULTA PRÉVIA}

No âmbito nacional, remonta à Constituição Federal de 1988 (CF/ 88), mais precisamente ao artigo n⿳ำ 68 do Ato das Disposições Constitucionais Transitórias (ADCT), o ordenamento jurídico que qualificou os grupos remanescentes de quilombos como sujeitos de direitos específicos, inclusive o direito de propriedade

\footnotetext{
De acordo com Roberto Kant de Lima (2002), a Antropologia do Direito (Anthropology of Law) compreende estudos comparativos de sistemas legais de diferentes culturas e sociedades, enquanto a Antropologia Jurídica (Legal Anthropology) é caracterizada pelas reflexões sistemáticas sobre o direito em suas diferentes manifestações culturais.
} 
das terras historicamente ocupadas. ${ }^{3}$ No âmbito internacional, destaca-se a Convenção $\mathrm{n}^{\mathrm{o}}$ 169, cuja interpretação, à luz da realidade brasileira, confere a povos e comunidades tradicionais - incluídos os remanescentes de quilombos os direitos reconhecidos pelo pacto da OIT a povos indígenas e tribais.

A OIT, criada pelo Tratado de Versalhes em 1919, começou a preocuparse particularmente com a situação desses povos entre as décadas de 1920 e 1930, quando realizou investigações e adotou instrumentos jurídicos internacionais para obrigar os Estados a suprimirem qualquer forma de trabalho forçado, a exemplo do trabalho escravo a que eram submetidos na América (FIGUEROA, 2009). Em 1957, diante das condições precárias de integração desses povos aos estados nacionais, a OIT adotou a Convenção n⿳ 107 Concernente à Proteção e Integração das Populações Indígenas e Outras Populações Tribais e Semitribais de Países Independentes (C107).

Criticada por seu caráter integracionista e assimilacionista, na medida em que pressupunha a irreversibilidade dos processos de "assimilação" ou de "integração" dos povos indígenas e outras populações às sociedades nacionais, a C107 foi revogada em 1989. Sucedeu-a a Convenção no 169 , adotada na $76^{\underline{a}}$ sessão da Conferência Geral da OIT, realizada em 7 de junho de 1989, em Genebra. Pautada em diversos instrumentos internacionais dirigidos ao combate da discriminação, entre os quais a Declaração Universal dos Direitos Humanos, o Pacto Internacional dos Direitos Econômicos, Sociais e Culturais, e o Pacto Internacional dos Direitos Civis e Políticos, a C169 inovou ao propor normas que reconhecem "as aspirações desses povos a assumir o controle de suas próprias instituições e formas de vida e seu desenvolvimento econômico, e manter e fortalecer suas identidades, línguas e religiões, dentro do âmbito dos Estados onde moram" (Preâmbulo).

Reconhecendo, também, que em diversos Estados nacionais "esses povos não podem gozar dos direitos humanos fundamentais no mesmo grau que o restante da população [...] e que suas leis, valores, costumes e perspectivas têm sofrido erosão frequentemente", a Convenção 169 considerou-os como sujeitos de direitos culturais, políticos, econômicos e para os fins que interessam aqui territoriais, determinando que:

Ao aplicarem as disposições desta parte da Convenção, os governos deverão respeitar a importância especial que para as culturas e valores espirituais dos povos interessados possui a sua relação com as terras ou

Longa discussão sobre a qualificação dos remanescentes de quilombos como sujeitos de direitos tem sido feita na Antropologia e no Direito, não sendo o caso de retomá-la aqui. Para aprofundamento sobre o tema, ver: Rios (2007), Arruti (2006), Leite (2008; 2012), Almeida (2002), O’Dwyer (2002; 2005) e Jorge (2017), entre outros. 
territórios, ou com ambos, segundo os casos, que eles ocupam ou utilizam de alguma maneira e, particularmente, os aspectos coletivos dessa relação (Art. 13).

No que concerne aos direitos territoriais dos povos indígenas e tribais,o Artigo 14 da C169 apresenta um mandamento fundamental ao reconhecer "explicitamente a usurpação de terras desde o domínio colonial", como alega Almeida (2008, p. 49), e salvaguar o direito desses povos a terras que não sejam ou estejam ocupadas exclusivamente por eles, mas às quais tenham tido acesso historicamente.

Dever-se-ão reconhecer aos povos indígenas e tribais os direitos de propriedade e posse da terra que ocupem tradicionalmente. Além disso, nos devidos casos, deverão ser adotadas medidas para salvaguardar o direito desses povos de utilizar terras que não sejam exclusivamente ocupadas por eles, mas às quais tradicionalmente tenham tido acesso para suas atividades tradicionais e de subsistência. Nesse particular, deverá ser dispensada especial atenção à situação de povos nômades e de agricultores itinerantes (Art. 14).

É de se destacar que a convenção adota a expressão "terras tradicionalmente ocupadas", a qual contempla diferentes formas de ocupação, dimensões e finalidades das relações desses povos com a terra, entendida como "a totalidade do habitat das regiões que os povos interessados ocupam ou utilizam de alguma outra forma" (Art. 13). Abrange, assim, múltiplos sentidos da noção de território, na medida em que remete a um conjunto de fatores como "as formas de ocupação e uso da terra e dos recursos naturais; às culturas e valores vinculados a essa terra [...] e à participação [no] uso, administração e conservação dos recursos mencionados" (SHIRAISHI NETO, 2007, p.47).

Por fim, a C169 incumbe Estados e governos de instituir e adotar todas as medidas necessárias, inclusive jurídicas, para garantir aos povos indígenas e tribais os efetivos direitos de posse e propriedade sobre as terras que ocupam tradicionalmente, bem como o direito de participar da gestão dos recursos naturais que nelas existam.

Para diversos Estados signatários da C169, seus mandamentos implicariam reformulações legislativas. Não é o caso do Brasil, pois a CF/88 já contempla, em boa medida, os fundamentos da convenção no que tange aos povos indígenas e às comunidades remanescentes de quilombos, ainda que a Carta Magna não aplique a essas últimas o conceito de "povos".

Note-se, sobre esse conceito, que o princípio basal da C169 é o da autodeterminação, o que, em determinados setores da sociedade brasileira, gerou 
temores em relação a uma possível desintegração do Estado Nacional motivada pela eventual fragmentação do povo brasileiro em diferentes povos. Tais temores, contudo, revelam-se injustificados, pois a própria convenção ressalta que "a utilização do termo 'povos'... não será interpretada como tendo implicação no que se refere a direitos que no direito internacional lhes possam ser conferidos" (TOMEI et. al. 1999 apud ALMEIDA, 2008, p. 50). Ou seja, a C169 não proporciona base para que a autodeterminação, confirmada pela Declaração das Nações Unidas sobre os Direitos dos Povos Indígenas, se traduza na forma de direitos de secessão.

Mesmo assim, as discussões geradas em torno da possível desagregação do povo brasileiro contribuíram para postergar a ratificação da C169 pelo Brasil. Embora ela tenha sido apresentada pelo Poder Executivo ao Congresso Nacional em 1991, a ratificação só ocorreria em 2002, e a sua promulgação pelo Presidente da República, em 2004.

De acordo com Figueiroa (2009, p. 22), outro foco de resistência à adoção da C169 no país foi a previsão de garantia da propriedade sobre as terras indígenas e tribais: "alguns legisladores argumentavam que o termo 'propriedade' contrariava o disposto na Constituição brasileira, que reconhece aos indígenas a posse permanente de terras que são propriedade da União" - explica. Porém, a própria autora adverte que, nesse mister, o Artigo 14, "concebido de forma a garantir direitos territoriais equivalentes ao de propriedade em relação ao uso da terra [deveria ser]lido em conjunto com o Artigo 34, que estabelece o princípio da flexibilidade na aplicação da Convenção, levando em conta as condições peculiares de cada país" (FIGUEIROA, 2009, p. 23).

Apesar da ressalva, o próprio reconhecimento de direitos associados aos diferentes modos de ser e estar que implicam territorialidades múltiplas no território nacional é suficiente para suscitar questionamentos acerca das condições de participação dos diversos grupos na sociedade brasileira. Para Almeida (2008), o desvelamento da pluralidade encoberta sob a noção singular e homogeneizante de "povo brasileiro" cria possibilidades de reinterpretação jurídico-formal de inúmeros agrupamentos sociais até então invisibilizados.

No caso da formação histórica brasileira pode-se dizer que tal dispositivo abre possibilidades para reconhecimento de múltiplas situações sociais que abarcam uma diversidade de agrupamentos tornados invisíveis pelas pretensões oficiais de homogeneização jurídica da categoria "povo" desde o período colonial. A pluralidade implícita na noção de "povos" publiciza diferenças. Ao mesmo tempo chama a atenção para territorialidades específicas, que têm existência efetiva dentro do significado de território nacional, apontando para agrupamentos constituídos no momento atual 
ou que historicamentes e contrapuseram ao modelo agrário exportador, apoiado no monopólio da terra, no trabalho escravo e em outras formas de imobilização da força de trabalho (ALMEIDA, 2008, p. 50).

Assim, o novo ordenamento jurídico no Brasil vem, consoante o pacto internacional, reconhecer uma diversidade de grupos que, não sendo indígenas nem tribais, assumem "uma expressão político-organizativa com critérios de representatividade próprios" (ALMEIDA, 2008, p. 52), de modo a se constituírem como sujeitos de direitos específicos. Neste sentido, vale destacar o Decreto $\mathrm{n}^{\circ}$ 6.040/2007, que, ao instituir política específica de desenvolvimento sustentável para povos e comunidades tradicionais, ${ }^{4}$ define-os como:

Grupos culturalmente diferenciados e que se reconhecem como tais, que possuem formas próprias de organização social, que ocupam e usam territórios e recursos naturais como condição para sua reprodução cultural, social, religiosa, ancestral e econômica, utilizando conhecimentos, inovações e práticas gerados e transmitidos pela tradição.

Compreendidos, pois, como "povos e comunidades tradicionais", os grupos remanescentes de quilombos fazem jus aos direitos previstos na Convenção 169, não restando dúvida de que suas prerrogativas devem ser observadas pelo Estado brasileiro. Foi, portanto, com base nesse fundamento que o MPF determinou a realização da consulta prévia às comunidades quilombolas potencialmente afetadas pelo projeto de exploração mineral na região de Trombetas, dando origem ao processo ora analisado.

Postulada como mecanismo obrigatório para assegurar que as necessidades e as prioridades de povos indígenas e tribais sejam refletidas nas decisões que os afetem, a consulta prévia, livre e informada é um dos temas mais controversos da C169 e um dos que mais têm sido discutidos na Comissão de Peritos na Aplicação de Convenções e Recomendações (CPACR) da OIT. Sua aplicação, na prática, tem sido objeto de frequentes embates entre povos, Estados e empresas no Brasil e na América Latina.

Com efeito, diversos observadores atestam que, em regra, ou a consulta tem sido mal conduzida, ou simplesmente não tem sido observada em diversos estados nacionais, o que constitui motivo de alarme para os povos afetados, sobretudo, por projetos desenvolvimentistas públicos e privados (SANJINÉS, 2010; SIMBAÑAS, 2012; GARZON; YAMADA; OLIVEIRA, 2016; SILVA,

\footnotetext{
O decreto também reconhece que tais grupos exercem territorialidades específicas que são perpassadas por razões práticas e simbólicas relativas à terra e aos recursos naturais. Por "terras tradicionalmente ocupadas" são entendidos "os espaços necessários à reprodução cultural, social e econômica dos povos e comunidades tradicionais, sejam eles utilizados de forma permanente ou temporária" (Art. $3^{\circ}$, II).
} 
2016). Christian Veloz, da OIT, resume: "A consulta tem vários problemas. Já participei na Colômbia de seminários com as mineradoras, povos indígenas e Ministério do Interior, é uma situação de guerra" (VELOZ, 2009, p. 64).

No Brasil, o direito à consulta prévia e de boa fé tem sido frequentemente desconsiderado no escopo de projetos de infraestrutura e de exploração de recursos naturais em áreas ocupadas por povos e comunidades tradicionais. A ausência ou a insuficiência de informação sobre a finalidade e os princípios que a consulta deve respeitar são, frequentemente, apresentadas como justificativas para a supressão desse processo. São comuns, também, alegações de que a legislação pátria não dispõe de regulamentação suficiente para orientar sua aplicação. Porém:

à luz do direito internacional [...] o resultado da aplicação da lei deve respeitar o princípio da boa-fé na aplicação dos tratados internacionais conforme o artigo 26 da Convenção de Viena, segundo o qual um Estado não pode argumentar sobre legislação interna de forma a elidir suas reponsabilidades no âmbito do direito internacional (FIGUEIROA, 2009, p. 62).

Neste sentido, a ratificação da Convenção n 169 pelo Brasil teria caráter vinculante. Dela decorreria, por exemplo, o compromisso de transformar em normas as suas disposições, inclusive a consulta prévia, não podendo o Estado brasileiro se omitir de fazê-la por falta de regulamentação específica. Da mesma forma, estaria o Estado obrigado a prestar contas à OIT sobre a aplicação das normas da Convenção no país (CALDAS, 2009).

A propósito, cumpre ressaltar que, embora algumas empresas venham adotando mecanismos de diálogo com as comunidades, aos quais pretendem atribuem o valor de "consulta", a consulta prévia estipulada na C169 é um dever do Estado que não pode ser transferido a outras partes. Ademais, em sua realização devem ser observadas condições apropriadas à livre e efetiva participação dos interessados, especialmente por meio de suas instituições representativas. A esse respeito, é claro o Art. $6^{\circ}$ da $\mathrm{C} 169$, ao determinar que as consultas “deverão ser conduzidas de boa-fé e de uma maneira adequada às circunstâncias, no sentido de que um acordo ou consentimento em torno das medidas propostas possa ser alcançado".

Por fim, a consulta caracteriza-se como “"um processo' [...] que abarca continuidade no tempo [e] permite o intercâmbio genuíno entre os governos e os povos potencialmente afetados" (FIGUEIROA, 2009, p. 41), em vista do estabelecimento de acordos em torno do consentimento e/ou da reparação de danos imputáveis a determinadas medidas. Logo, não pode se resumir a mera 
formalidade na transmissão de informações aos interessados; a consulta deve, ao contrário, consistir efetivamente numa oportunidade para que os grupos influenciem o resultado dos processos decisórios que a eles concernem.

O que se viu no caso do Trombetas, porém, foi algo bem distinto: uma série de mal-entendidos, divergências entre os envolvidos e cisões entre os próprios quilombolas que, juntos, haviam sido responsáveis pela deflagração do Inquérito Civil que suscitou a consulta. Embora dramático para indivíduos e grupos que dele participaram, o processo aqui analisado é tão rico como objeto de pesquisa jurídica e antropológica quanto o foi como experiência de aprendizado sobre o funcionamento do campo do direito para os líderes locais que protagonizaram o processo de consulta.

\section{A CONSULTA COMO DRAMA SOCIAL}

A lavra de bauxita na região do Trombetas, que responde pelo maior volume de produção desse minério no Brasil, remonta à década de 1970, quando a Mineração Rio do Norte - criada pelo grupo Alcan do Brasil em 1967 - se instalou na company town Porto Trombetas, construída para abrigar seus funcionários e sediar suas operações. $\mathrm{Na}$ época, inexistia o aparato jurídico de que as comunidades quilombolas atualmente dispõem para proteger seu ambiente natural e cultural, de modo que pequenas barganhas se tornaram usuais entre a mineradora e as comunidades, como relata um morador:

A mineração, quando entrou, [...] eles fizeram umas propostas e tanto. A gente tinha remédio, falaram que tinha dentista de graça [...], eles colocaram uma imensa lista que ia ter direito. Enquanto depois eles foram cortando aos poucos, aos poucos. Quer dizer, então, mesmo a gente naquele tempo, se ela não mentisse para nós, nós estaria mais ou menos (CUMBUCA NORTE, 2016, p. 180).

Com as mudanças relativamente recentes na legislação que ampara as comunidades quilombolas no Brasil, o cenário para a implantação de novos projetos minerários na bacia do Trombetas se alterou significativamente. Logo, quando se tratou da movimentação da MRN, em 2012, para iniciar o processo de licenciamento ambiental ${ }^{5}$ e realizar os estudos de detalhamento geológico ${ }^{6} \mathrm{dos}$

5 O processo tem início com a elaboração do Estudo de Impacto Ambiental (EIA), que constitui peça técnica obrigatória no âmbito do Licenciamento Ambiental no Brasil. No caso da ZCO, incidente em áreas ocupadas e reivindicadas por comunidades quilombolas, além do EIA deve-se realizar um Estudo do Componente Quilombola (ECQ), conforme exige a Portaria Interministerial no 60/2015.

6 Estudos que visam ao detalhamento das qualidades da bauxita encontrada nos platôs. 
platôs da chamada Zona Central Oeste $(\mathrm{ZCO}){ }^{7}$ líderes quilombolas, apoiados pela Associação das Comunidades Remanescentes de Quilombos do Município de Oriximiná (Arqmo) e pela Comissão Pró-Índio de São Paulo (CPI-SP), prestaram denúncia ao MPF.

Ao cindir as relações correntes entre empresa e comunidades, a denúncia instaura o drama social enquanto "processo anarmônico ou desarmônico que surge em situações de conflito" (TURNER, 2008, p. 33) e é marcado por quatro fases: 1) ruptura; 2) crise e intensificação da crise; 3) ação reparadora; e 4) desfecho (que pode levar à harmonia ou cisão social). De acordo com Turner (2008, p. 34),

[...] a ruptura de relações formais, regidas pela norma, ocorre entre pessoas ou grupos dentro do mesmo sistema de relações sociais [...]. Tal ruptura é sinalizada pelo rompimento público e evidente, ou pelo descumprimento deliberado de alguma norma crucial que regule as relações entre as partes [...]. Uma violação dramática pode ser praticada por um indivíduo, certamente, mas ele sempre age, ou acredita agir, em nome de outros indivíduos, estejam eles cientes disto ou não. Ele vê a si mesmo como um representante, e não como um agente solitário.

Como se depreende do relato de um quilombola, a ruptura, no caso estudado, é representada como uma briga:

Foi nesse momento que a gente veio a briga, a gente paralisou eles. Porque uma vez um cara do Ibama falou: "Eu não sei se existe quilombola naquela região. Sei que tem gavião real”. Olha só, um cara do Ibama, que dá autorização de entrada, sabe que tem um gavião real ali no Monte Branco, ${ }^{8}$ mas não sabe que tem comunidade quilombola. Aquilo ali foi um murro que deram na nossa barriga, e a porrada desceu lá dentro. Daí, só teve a consulta prévia porque nós denunciamos. Aí que nós falamos: “Tem que ter a consulta prévia, senão não rola”. Então, a consulta prévia trouxe essas informações para nós. A mineração, sabe o que ela fazia? Eles vieram uma vez aqui só para dizer que já iam explorar [...]. Ela já fala em explorar, instalar (CUMBUCA NORTE, 2016, p. 217).

Envolta em alta carga moral, a denúncia dos quilombolas corresponde à percepção da desconsideração com que são tratados não só pela mineradora, mas também pelo Estado. Afinal, o órgão responsável pelo processo de licenciamento ambiental não levara em conta as comunidades quando da emissão de autorizações para a empresa realizar estudos em áreas da ZCO que, apesar de estarem nos

\footnotetext{
Os platôs Escalante, Rebolado, Cruz Alta Leste, Jamari, Barone, Cruz Alta e Peixinho, adquiridos da Alcoa e da Billiton Metais em 1992, integram a chamada Zona Central Oeste. A divisão em zonas faz parte da estratégia de lavra da empresa, considerando sua previsão de permanência na região pelos próximos 40 anos, assim como os períodos de esgotamento das minas.

8 Platô em fase de exploração pela MRN, localizado no TQ Alto Trombetas II.
} 
limites da Floresta Nacional de Saracá-Taquera, estão em processo de titulação em favor delas. Mais que isso, corresponde à dolorosa percepção dos quilombolas de que, simplesmente, sua existência é negada pelo Estado, reforçada por uma moradora: "Em Brasília consta que aqui mora só gavião real, que não tem nada, só um gavião real" (informação verbal). Como explica Leite (1996, p. 41),

não é que o negro não seja visto, mas sim que ele é visto como não existente. É interessante observar que este mecanismo, posteriormente percebido também no Brasil, ocorre em diferente regiões e contextos, revelando-se como uma das principais formas de racismo a se manifestar. Como um dispositivo de negação do Outro, muitas vezes inconsciente, é um produtor e reprodutor do racismo. A invisibilidade pode ocorrer no âmbito individual, coletivo, nas ações institucionais, oficiais e nos textos científicos (Grifos da autora).

Em meio às sucessivas demonstrações de desconsideração aos quilombolas, o MPF, ao acolher sua denúncia e instaurar o Inquérito Civil, em 2012, foi o primeiro a tratá-los como sujeitos de agência, isto é, dotados da capacidade de processar a experiência social e reagir de modo a provocar mudança, mesmo estando em posições de subordinação (GIDDENS, 2009). Como ressaltam Long e Ploeg (2011), seguindo Giddens (2009), os sujeitos subordinados podem influenciar ações dos superiores na medida em que mobilizem recursos disponíveis nas próprias relações de dependência e subordinação. No caso em apreço, o recurso ao MPF marcou uma nova fase de enfrentamento da situação de desconsideração e desrespeito de direitos, historicamente vivenciada pelas comunidades quilombolas.

As primeiras providências no âmbito do ICP pretenderam apurar a legalidade das ações da mineradora e dos órgãos ambientais envolvidos no processo. Instado a manifestar-se, o Instituto Brasileiro do Meio Ambiente e dos Recursos Naturais Renováveis (Ibama) limitou-se a informar que se encontrava em fase de análise o Termo de Referência para elaboração do EIA/Rima da ZCO. Já a MRN informou que vinha realizando trabalhos para obter melhor conhecimento da mineralização da bauxita e enfatizou que possuía autorização de supressão vegetal para tanto, concedida pelo Instituto Chico Mendes de Conservação da Biodiversidade (ICMBio):

Em relação à abertura de ramais no Platô Cruz Alta, destaca-se que, antes mesmo de iniciar as tratativas junto a órgãos ambientais competentes, em 09/03/2012, a MRN se reuniu com a comunidade Mãe-Cué para informar sobre o planejamento dos trabalhos de detalhamento geológico no Platô Cruz Alta. Em 07/07/2012 devidamente autorizada pelo ICMBio, a MRN iniciou os trabalhos de limpeza dos ramais. E, em 04/09/2012, após a 
conclusão de abertura do ramal principal, a MRN reuniu-se novamente com a comunidade Mãe-Cué para informar sobre o início dos trabalhos de abertura dos ramais secundários (IC/MPF n⿳ำ 1.23.002.000480/2012-81).

Em despacho, o MPF destacou a preocupação, do ponto de vista ambiental e do ponto de vista humano, para com as comunidades quilombolas da região e evocou a necessidade da consulta prévia quanto a eventuais medidas administrativas, tais como a expedição de licenças, que venham a afetá-las:

Não se trata apenas da necessária concretização do direito de consulta previsto na Convenção 169, mas de garantir o direito fundamental dos povos quilombolas de ter preservado seu modo de vida, de ter preservado o direito ao seu território nos termos do art.68 do ADCT, de ter preservado seu direito à informação. Entende-se que não é possível alijar as comunidades quilombolas mesmo nas discussões preliminares de um empreendimento que pode causar dano tão considerável para a terra que reivindicam [...]. A presença quilombola no local é de conhecimento notório, não é aceitável que reste invisível do ponto de vista jurídico, sendo imprescindível que seja considerada tal presença pelo empreendedor e órgãos públicos de fiscalização e licenciamento (IC/MPF no 1.23.002.000480/2012-81. Grifo dos autores).

A partir desse despacho, a consulta pautada pela C169 é apresentada pelo MPF como oportunidade privilegiada para que os quilombolas participem "ativamente (apesar de nem sempre no nível de consciência discursiva) na construção de seus próprios mundos sociais, apesar de [...] as circunstâncias que eles encontram não serem simplesmente fruto de sua própria escolha" (LONG; PLOEG, 2011, p. 26). Contudo, a compreensão do direito que o MPF buscava assegurar-lhes não é imediata, dando margem a dissensões entre as próprias comunidades, alimentadas por entendimentos diferenciados do que deveria ser a consulta, como ilustra um entrevistado:

Olhe, na verdade, de início, eu lhe juro que eu não tinha noção realmente de que era uma consulta, logo no início eu estava meio perdido, mas com o parecer do MPF, começamos a entender realmente o que era uma consulta, porque para nós isso foi exótico, né?! Isso nunca tinha acontecido. Não imaginava que esse era um direito nosso. Eu, pelo menos, não tinha conhecimento que a consulta prévia é um direito nosso. Comecei a ficar sabendo que era um direito quilombola a partir de 2012. Através do MPF nós começamos a ficar sabendo que era um direito nosso e que ela tinha que ser feita. Porque, de início nós entendemos que ela podia ser feita de qualquer jeito, somente uma reunião com as comunidades, só para saber quem era a favor ou contra a mineração realizasse os estudos ou não. E já estava tudo resolvido [...] Mas depois vem o MPF e diz tudo diferente: "Não, vocês vão ter que fazer a consulta, ela tem que ser feita por fases, 
ela tem que ser feita por etapas, porque ela tem que ser prévia, livre e informada". E daí, nós fomos tomando consciência do que realmente era uma consulta e começamos a fazer (Entrevista concedida na comunidade Juquirizinho, 18.02.2017).

$\mathrm{Na}$ prática, contrariando as expectativas iniciais de um processo livre e informado, a consulta se desmembraria em conturbados eventos que, sucessivamente, viriam a anular resultados uns dos outros. Gerando desgastes entre os próprios moradores das comunidades e entre outros atores envolvidos no drama, tais como as associações quilombolas, a MRN, os órgãos ambientais e

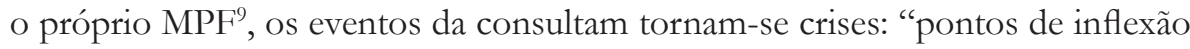
ou momentos de perigo e suspense, quando é menos fácil vestir máscaras" (TURNER, 2008, p. 34).

Primeiro, reagindo ao posicionamento do procurador do $\mathrm{MPF}$, os advogados da MRN questionam se a consulta prévia é o instrumento adequado, já que a procuradoria do Ibama teria salientado que o procedimento correto para o caso seria a audiência pública, a qual só poderia ser realizada após a elaboração de estudos previstos nos ritos do licenciamento ambiental. Ademais, a procuradoria do órgão nega aos quilombolas o reconhecimento como legítimos ocupantes das terras em questão:

Esclareço que os citados platôs encontram-se dentro da Floresta Nacional Saracá-Taquera e não em terras quilombolas [...]. Esclareço, também, que um dos instrumentos de diálogo com as comunidades afetadas do empreendimento são as audiências públicas nas quais serão dirimidas dúvidas e recolhidas as dúvidas e sugestões frente à apresentação dos estudos ambientais. Porém, essas são realizadas apenas após a elaboração dos estudos, sendo as considerações das comunidades inseridas na análise do processo. [...] somente os estudos ambientais poderão indicar quais serão as comunidades que serão afetadas (IC/MPF no⒈23.002.000480/2012-81).

Chamada à ação, a Fundação Cultural Palmares (FCP), ${ }^{10}$ que é o órgão federal responsável pela implementação de políticas públicas voltadas para os grupos afro-brasileiros, esclarece a diferença entre audiência pública e consulta prévia, ratificando que essa última está prevista em casos que envolvam

9 Vários outros atores participaram eventualmente do IC, especialmente quando convocados a prestar informações ou a assessorar as comunidades, entre os quais o Ministério Público do Estado do Pará (MPE-PA), o Incra, a Comissão Pastoral da Terra (CPT), a Ufopa e outros. Devido ao escopo deste texto, não serão considerados aqui.

10 A Fundação Cultural Palmares (FCP) foi criada em 22 de agosto de 1988, instituição vinculada ao Ministério da Cultura (MinC) com o objetivo de promoção e preservação da arte e da cultura afrodescendente. É responsável por emitir certificações para comunidades quilombolas, documento que reconhece os direitos das comunidades quilombolas e dá acesso aos programas sociais do Governo Federal, bem como, é documento fundamental para processo de titulação do território quilombola. 
comunidades quilombolas. Nesse ínterim, o MPF recomenda à FCP que inicie imediatamente, no início de 2013, o procedimento de consulta prévia às comunidades. Atribui-lhe, então, as seguintes medidas: i) elaborar plano de consulta com informações básicas sobre o objeto da consulta, os principais interlocutores e o tempo necessário para as comunidades assimilarem o objeto; ii) coletar e repassar informações sobre o empreendimento em linguagem clara e objetiva para as comunidades; iii) submeter o plano de consulta aos principais intervenientes.

Nesse ínterim, o Ibama e o ICMBio acatam recomendação do MPF para que suspendessem licenças ou autorizações para atividades da MRN na área de pretensão quilombola, até que ocorresse a consulta, o que motiva a mineradora a buscar formas alternativas de diálogo com as comunidades.

Assim, a empresa criou um Grupo de Trabalho (GT) com representantes das comunidades potencialmente afetadas pelo projeto de mineração que pretendia executar. Esse GT, que se reunia mensalmente na sede da mineradora para debater aspectos do projeto minerário e eventuais compensações para as comunidades, foi duramente criticado por quilombolas que questionavam a legitimidade dos representantes no grupo e pelo MPF, que demandou a rigorosa observância dos preceitos legais e recomendou à empresa abrir mão de fóruns que desviassem a atenção da consulta prévia, livre e informada, que estava a cargo da Fundação Palmares. ${ }^{11}$

Ocorre que, em junho de 2014, representantes das comunidades quilombolas e da CPI-SP informam ao MPF que a FCP teria realizado eventos inadequados a título de consulta, nos quais não teria havido expressiva representatividade quilombola. Segundo eles, apenas um pequeno grupo teria participado das decisões, então encaminhadas sob pressão da MRN:

a Fundação Cultural Palmares, juntamente com o prefeito, o vice prefeito e vereadores do Município de Oriximiná, além de representantes da Mineradora Rio do Norte, realizaram reuniões com alguns comunitários, para tratar, inicialmente, sobre o tema genérico “educação", e que, ao final, foi realizada uma espécie de "consulta" para a concessão da autorização pretendida para o estudo de mineração (IC/MPF no 1.23.002.000480/2012-81).

Mais uma vez, em agosto de 2014, o MPF oficia à FCP para que iniciasse a consulta prévia, nos termos previstos em lei, no prazo máximo de dez dias. Em seguida, a CPI-SP reporta ao MPF sobre a atuação da FCP:

11 A empresa desfez o GT, mas, na sequência, adotou a realização de encontros mensais nos territórios quilombolas para manutenção de grupos de diálogo. 
A consulta não se resume a um concordar ou não com a atividade da mineradora, mas também em estabelecer em quais condições ela poderá ser realizada para minimizar impactos para as comunidades [...] É, no mínimo, estranho que o órgão responsável por conduzir a consulta prévia aos quilombolas desconheça a atividade que é objeto da consulta. E se não dispõe de informações sobre os estudos, é de se supor que também não tenha uma avaliação de seus impactos, nem tão pouco condições de propor medidas de controle e de mitigação decorrentes desses impactos (IC/MPF no 1.23.002.000480/2012-81).

Os desentendimentos entre os órgãos de Estado, a organização não governamental e os quilombolas vão fazendo da consulta prévia, na qual depositavam esperança, um assunto indigesto para os últimos. A crise se intensifica, de acordo com as palavras de Turner (2008, p. 33), e há "uma tendência de que a ruptura se alargue, ampliando-se até se tornar tão coextensiva quanto uma clivagem dominante no quadro mais amplo de relações sociais relevantes ao qual as partes conflitantes ou antagônicas pertencem".

Finalmente, em setembro de 2014, a Associação das Comunidades Remanescentes de Quilombo do Município de Oriximiná (Arqmo) oficia ao MPF afirmando que os quilombolas não queriam mais realizar uma consulta prévia aos estudos que a MRN pretendia desenvolver, mas sim aplicar a consulta na fase do licenciamento ambiental do empreendimento. Em seu entendimento, depois dos chamados "estudos da mineração", como costumam chamar o detalhamento geológico, o EIA e outras atividades conexas, eles fariam a consulta para determinar posições quanto ao projeto em si de exploração de bauxita na área.

Para Scaramuzzi (2017, p. 78), a manifestação da Arqmo expressa "a fragmentação interna e a discordância da população quilombola acerca da melhor decisão a ser tomada no impasse com a mineradora", a qual o autor interpreta como efeito de "diferentes formas de se relacionar com a empresa, por parte dos quilombolas das comunidades da Área Trombetas 2 e das mais distantes, da Área Trombetas 1". Com efeito, quilombolas envolvidos diretamente na organização das reuniões da consulta se ressentiram de cisões entre as duas áreas. Alguns, inclusive, alegam ter sofrido injúrias e difamações por parte de outros quilombolas, que os teriam acusado de serem "vendidos à mineração" e não agirem com boa-fé.

Na sequência, a MRN solicita ao MPF “uma efetiva intervenção nas ações coordenadas pelas entidades do terceiro setor, uma vez que os princípios da consulta preconizados pelo MPF estão sendo ignorados por seus representantes nessas ações", assim como que "seja disponibilizada a realização imediata de reunião entre o MPF e os verdadeiros representantes das comunidades do Alto 
Trombetas I e II para os devidos esclarecimentos e correção do direcionamento que está sendo dado ao processo". Ademais, por intermédio de seus advogados, a MRN solicita que sejam retomadas as autorizações para realização dos estudos socioambientais.

Às questões colocadas o MPF responde, em outubro de 2014, com um extenso relatório no qual julga que o documento apresentado pela Arqmo "não é apto o suficiente para afastar o direito à realização do processo de consulta, já que existem parcelas consideráveis das comunidades quilombolas afetadas que desejam exercê-lo". No entendimento da procuradoria federal, a consulta prévia é um direito indisponível:

Estamos a tratar de interesses de comunidades tradicionais quilombolas. Povos, esses, historicamente perseguidos pelo Estado e, quando passaram a não lhes serem mais economicamente interessantes, foram relegados à invisibilidade e ao abandono. [...] Essas comunidades são invisíveis aos olhos do Estado e assim tendem a permanecer diante da falta de exercício de direitos de participação que poderia, de alguma forma, alterar o panorama historicamente verificado. Ao considerar que parte das lideranças quilombolas apresentou declaração formal de negativa participação no processo de consulta prévia para a autorização de estudos minerários e detalhamento geológico, e que a consulta é um direito que pode não pode ser exercido pelo seu titular (já que ninguém é obrigado a exercer um direito que lhe prestigia), somado, mais uma vez, o respeito à autodeterminação que acompanha tais comunidades, não lhe persistiria a condição válida para a realização do processo de consulta. Contudo [...], duas questões hão se ser enfrentadas: a) a representatividade e a legitimidade daqueles que subscrevem a manifestação (não querem estudos) e os direitos das maiorias, já que parte considerável das comunidades manifestou perante essa procuradora da República o interesse e o firme propósito na realização da consulta; b) parte importante da fase de autorização de continuidade dos estudos e detalhamento geológico não está definida, qual seja, a indenização cabível pelo uso da terra, nos termos do art.27 do Código de Minas, pois seria objeto de discussão durante o processo de consulta, conquanto independente de sua realização.[...] o art.27 merece leitura constitucional quanto a dois aspectos: a)legitimidade das comunidades quilombolas recebem a indenização: em que pese ainda não existir titulação para a maior parcela territorial das comunidades atingidas, os respectivos processos administrativos de reconhecimento da propriedade encontramse em trâmite. De mais a mais, o próprio art. 27 alude a simples condição de possuidor já confere direito a indenização; b) os danos e prejuízos apontados pelo art.27 não se resumem àqueles meramente materiais, já que alcançam também os danos e prejuízos imateriais causados às comunidades locais [...] (IC/MPF no 1.23.002.000480/2012-81). 
Por outro lado, na visão de alguns quilombolas que haviam participado dos eventos compreendidos como parte da consulta, já cansados de suas idas e vindas e desacertos, o MPF lhes havia retirado o direito de decidir sobre o objeto e os termos da consulta: "primeiro mostrou o nosso direito, depois tirou o nosso direito”. Para um líder comunitário que participara de todo o processo até então, a sequência de erros a que teriam sido induzidos pelo próprio Estado conduzia ao descrédito em relação ao direito que a C169 pretendeu assegurar:

Tem que fazer consulta, a Palmares faz a consulta, a consulta não está certa, o MP não aceita, tem que refazer, a gente refaz, depois dizem que não foi feita. A gente não sabe mais o que fazer, se a gente errou é porque foi orientado, ninguém aqui se vendeu à mineração, ninguém tem nada (Entrevista concedida em Santarém, 2016).

Chega-se, assim, a um momento limítrofe do processo social vivenciado em torno da consulta prévia, no qual valores e pactos previamente acordados estão abalados, e a crise pública assume o que Turner (2008, p. 34) chama de:

[...] características liminares, uma vez que se trata de um limiar entre fases relativamente estáveis do processo social, embora não seja um 'límen' sagrado, cercado de tabus e afastado dos centros da vida pública. Pelo contrário, ele assume seu aspecto ameaçador dentro do próprio fórum e, por assim dizer, desafia os representantes da ordem a lidar com ele. Não pode ser ignorado ou desprezado.

Nessa fase do drama social, medidas de reparação são exigidas no intuito de limitar a difusão da crise e restabelecer relações em meio ao conflito. Tais medidas corretivas, segundo Turner (2008, p. 34), constituem "'mecanismos' de ajuste e regeneração [...], informais ou formais, institucionalizados ou ad hoc [...] operacionalizados por membros de liderança".

No caso em tela, ratificada a obrigatoriedade do procedimento recomendado dois anos antes, torna-se necessário recomeçar, em fins de 2014, todo o processo de consulta. Desta vez, no contexto de disputas entre comunidades quilombolas, órgãos de Estado e mineradora, ainda mais conturbado pelas oposições internas agravadas entre as primeiras e pelas percepções e expectativas de direitos divergentes verificadas entre os diferentes partícipes do Inquérito Civil, o MPF optou pela estratégia de criar um grupo de trabalho com lideranças quilombolas para dar andamento às etapas da consulta prévia, livre e informada preconizada pela C169. Esse grupo ficaria, então, responsável pela condução de reuniões nos territórios Alto Trombetas I e Alto Trombetas II, as quais viriam a se desenrolar até o segundo semestre de 2016. 
Documentos anexados no IC, denominados "Relatórios das reuniões de todas as etapas do plano de consulta realizado nas comunidades do Alto Trombetas I e II", demonstram que esse grupo realizou duas rodadas de reuniões consultivas nos territórios: a primeira para aprovar o plano de consulta que seria implementado, e a segunda para decidir sobre a forma de avaliação dos impactos causados pelos estudos que a mineradora pretendia realizar. Das atas acostadas no IC depreende-se que cada evento reunia moradores de uma ou mais comunidades, conforme sua conveniência (em função de critérios como quantidade de pessoas e proximidade geográfica).

As reuniões de cada rodada seguiram uma metodologia própria para construir uma posição coletiva sobre os "estudos da MRN nos platôs Zona Central e Oeste". Na primeira rodada, os organizadores do evento passavam cópias do plano de consulta para todos os participantes e, posteriormente, discutiam o conteúdo do plano. Ao final, os participantes votavam pela aprovação do plano. $\mathrm{Na}$ segunda rodada de reuniões, debatiam e deliberavam se contratariam uma empresa para avaliar e valorar impactos dos estudos prévios ao empreendimento ou se fariam uma negociação direta com a mineradora, ${ }^{12}$ decidindo-se pela primeira opção. Como disse uma liderança quilombola em uma das reuniões, as discussões deveriam se pautar por critérios utilizados pelo MPF, reformulados segundo seu entendimento:

fazer valer a democracia de um direito dos quilombolas e povos tradicionais, que a PR pediu que as lideranças conversassem entre si para chegar num bom senso, isso aconteceu, e vamos fazer valer esse direito. Aonde a mesma sugeriu que podemos negociar com a empresa ou até contratar uma empresa para avaliar os impactos e deixou claro que esse pagamento será em formas de projetos e benefícios coletivos, e disse que é para ser de forma bem participativa, a decisão será de forma de votação secreta, e aí o povo decide [...] (IC/MPF no 1.23.002.000480/2012-81).

Os episódios que ocorreram ao longo das duas rodadas de consulta confluíram, ao fim de 2015, para um acordo quanto ao seu resultado, no caso, favorável à realização dos estudos pela mineradora - realizados em 2016 e 2017. Em contrapartida, a empresa assumiu o compromisso de proceder a outro estudo, solicitado pelo MPF, com a finalidade de mensurar eventuais perdas sofridas pela comunidade - não executados, até o momento. Desse modo, o processo relativo à consulta encerrou-se com um (não)desfecho, que, para Turner, consistiria em uma fase de reintegração, assim apresentada:

12 Em seu horizonte, havia a perspectiva de receberem algum valor financeiro pelos impactos causados e pelo tempo de uso do território durante a realização dos estudos. 
A última fase que ressalto consiste na reintegração do grupo social perturbado ou no reconhecimento e na legitimação social do cisma irreparável entre as partes do conflito. Do ponto de vista do observador cientifico, a quarta fase - aquela do clímax, solução ou resultado temporário - é uma oportunidade para se fazer o balanço. [...]. Novas normas e regras terão sido geradas durante tentativas de remediar o conflito: velhas regras terão caído em descrédito e sido abolidas (TURNER, 2008, p. 35).

Após o acordo, porém, houve reivindicações de invalidação da consulta por parte de alguns quilombolas, as quais foram negadas pelo MPF, intenso processo de troca de acusações e mágoas que se instalou entre os próprios quilombolas dos territórios Alto Trombetas I e II, uns apontando os outros como adversários em uma disputa que transformou diferenças em fragmentação, e não em reintegração.

\section{CONSIDERAÇÕES FINAIS}

Quando os quilombolas foram envolvidos no IC, e instados à realização da consulta prévia sobre a mineração na região de Trombetas, não tinham clareza de que esse era um direito seu, nem de como proceder na implementação desse direito. Sua perspectiva só começou a ser modificada a partir dos diálogos com o MPF, quando a consulta prévia passou a ser vislumbrada como oportunidade potencialmente reparadora - senão no plano material, pelo menos na dimensão simbólica do reconhecimento como sujeitos de direitos. Desde então, a temática da consulta prévia adquiriu um lugar central na vida política e comunitária dos quilombolas, mobilizando-os ao longo de mais de dois anos e trazendo-lhes saldos positivos e negativos.

Por um lado, é inegável que a consulta - apesar de questionada e postergada em várias ocasiões, não só pela mineradora, mas também pelo Estado e até mesmo por alguns de seus representantes - logrou conferir visibilidade moral às comunidades quilombolas. Como se tentou demonstrar, em que pese ao arcabouço jurídico específico que a elas se aplica no Brasil, é notório que essas comunidades não veem contempladas suas percepções e expectativas específicas de direitos, restando, na prática, desconsideradas ou pouco valorizadas na esfera jurídica-administrativa.

Por outro lado, os inequívocos atropelos observados na realização da consulta fizeram do exercício desse direito mais uma arena de disputas entre os envolvidos no inquérito, inclusive, alimentando desavenças e acusações entre quilombolas, na ausência de posições claras e consoantes por parte dos órgãos de 
Estado. Considerando que a este caberia o dever de realizar a consulta, conforme a C169, a condução da mesma por diferentes atores, em etapas que sucessivamente anularam umas as outras, frustrou tanto as expectativas dos quilombolas de um honesto "pedido de licença" da empresa para usar áreas que ocupam, quanto a lisura do processo consultivo. Sobre esse ponto, Scaramuzzi (2017, p. 74) afirma:

É possível averiguar na documentação do Inquérito Civil Público que os quilombolas, em um contexto de extrema disparidade de poder e vOz, enxergaram nesse diálogo e nessa negociação com a mineradora a possibilidade de tentar resolver os impasses relativos à regularização fundiária e às demandas de melhora ou implantação de serviços públicos, que são obrigações estatais e não têm nenhuma relação com a mineradora. Outro dado que revela o conjunto de atas é que a maior parte das reuniões realizadas para a discussão do assunto foi com a presença de funcionários da MRN. Em nenhum momento houve uma reunião exclusiva com os quilombolas e todos os órgãos estatais envolvidos no caso, como Ibama, ICMBio, Fundação Cultural Palmares e Incra, sem a presença de pessoas ligadas à mineradora.

Está claro que enfrentamentos ocorridos na implementação da consulta foram agravados pela própria disparidade entre pontos de vista e demandas dos diferentes atores envolvidos no processo. A sucessão de eventos no Trombetas ensina, portanto, que se a consulta prévia se pretende um instrumento de justiça para povos e comunidades tradicionais, faz-se necessário, em cada caso de sua aplicação, considerar as situações específicas atravessadas por percepções e expectativas de direitos diferenciadas.

Para um Estado que não se exima do dever de executar a consulta prévia, livre e informada como garantia do direito que têm aqueles povos e comunidades, de participarem dos processos decisórios que as afetem, cabe reconhecer a existência de perspectivas legitimamente dissonantes sobre a consulta. De outra forma, a sua operacionalização, ainda que obediente às diretrizes gerais da C169, arrisca frustrar o gozo de direitos por parte das próprias comunidades que o processo intenta proteger.

Tomada como um drama social, a consulta sobre a mineração em Trombetas mostra-se, enfim, extremamente complexa. A breve narrativa do caso ilustra o caráter altamente dramático que a implementação desse direito assumiu entre os quilombolas, para muito além do processo acusatório que engendrou, o qual, apesar de eloquente, contribui de forma muito limitada para a compreensão efetiva do que está em jogo entre os partícipes da consulta.

Trata-se, também, de um caso emblemático para a compreensão da multiplicidade de pontos de vista e estratégias de ação acionadas por comunidades 
tradicionais sobre o campo jurídico, o qual, em regra, lhes é refratário. Neste sentido, envolvidos em uma série de eventos encadeados na estrutura de um campo social sobre o qual construíram interpretações e interesses divergentes, os quilombolas do Trombetas, enquanto sujeitos dotados de agência, lograram resultados ao promover desequilíbrios nas relações de poder pré-estabelecidas no conflito que a consulta tematizou.

\section{REFERÊNCIAS}

ACEVEDO, R.; CASTRO, E. Negros do Trombetas: guardiães de matas e rios. Belém: UFPA-NAEA, 1993.

Mobilização política de comunidades negras rurais: domínios de um conhecimento praxiológico. Novos Cadernos NAEA, Belém, v.12, n 2, p.73106, dez. 1999.

ALMEIDA, A. W. B. de. Os quilombos e as Novas Etnias. In: O’DWYER, E. C. (Org.). Quilombos: Identidade Étnica e Territorialidade. Rio de Janeiro: Editora FGV, 2002.

Terra de quilombo, terras indígenas, "babaçuais livre”, "castanhais do povo", faixinais e fundos de pasto: terras tradicionalmente ocupadas. Manaus: PGSCA-UFAM, 2008.

ARRUTI, J. M. Mocambo: antropologia e história do processo de formação quilombola. Bauru-SP: Edusc, 2006.

CALDAS, F. A participação cidadã no sistema de monitoramento da OIT e ao papel da CUT. In: CONVENÇÃO 169 DA OIT SOBRE POVOS INDÍGENAS E TRIBAIS: oportunidades e desafios para sua implementação no Brasil, 2009, São Paulo. Anais... São Paulo: Instituto Socioambiental, 2009. p. 274-277.

CUMBUCA NORTE. Estudo do componente quilombola das comunidades localizadas no entorno da Mineração Rio do Norte. Santarém, 2016. 632 p.

FIGUEROA, I. A Convenção 169 da OIT e o dever do Estado brasileiro de consultar os povos indígenas e tribais. In: CONVENÇÃO 169 DA OIT SOBRE POVOS INDÍGENAS E TRIBAIS: oportunidades e desafios para sua implementação no Brasil, 2009. São Paulo. Anais... São Paulo: Instituto Socioambiental, 2009. p. 13-48. 
GARZÓN, B.; YAMADA, E.; OLIVEIRA, R. Direito à consulta e consentimento de povos indígenas, quilombolas e comunidades tradicionais. São Paulo: Rede de Cooperação Amazônica-RCA; Washington DC: DueProcessof Law Foundation, 2016.

GIDDENS, A. A constituição da sociedade. São Paulo: Martins Fontes, 2009. JORGE, A. L. O processo de construção da questão quilombola: discursos em disputa. Rio de Janeiro: Gramma, 2016.

KANT DE LIMA, R. Cultura Jurídica e Administração de Conflitos: a questão da apropriação particularizada dos espaços públicos. In: CONGRESSO LUSO AFRO BRASILEIRO DE CIÊNCIAS SOCIAIS: AS CIÊNCIAS SOCIAIS NO ESPAÇO DE LÍNGUA PORTUGUESA, 6. Anais... Faculdade de Letras, Universidade do Porto, 2002, v. 1, p. 261-264.

LEITE, I. B. (Org.) Negros do Sul do Brasil: invisibilidade e territorialidade. Florianópolis: Letras Contemporânea, 1996.

Terras de quilombos. In: LIMA, A. C. de S. (Coord.). Antropologia e direito: temas antropológicos para estudos jurídicos. Rio de Janeiro; Brasília: Contracapa; LACED; ABA, 2012. p. 356-368.

O projeto político quilombola: desafios, conquistas e impasses atuais. Estudos Feministas, v. 16, n. 3, 2008.

LONG, N.; PLOEG, J. D. van der. Heterogeneidade, ator e estrutura: para a reconstituição do conceito de estrutura. In: SCHNEIDER, S.; GAZOLLA, M. (Orgs.). Os atores do desenvolvimento rural: perspectivas teóricas e práticas sociais. Porto Alegre: UFRGS Editora, 2011. p. 62-90.

O’DWYER, E. C. (Org.). Quilombos: identidade étnica e territorialidade. Rio de Janeiro: Editora FGV, 2002.

Os quilombos e as fronteiras da Antropologia. Antropolítica, NiteróiRJ: UFF, v. 10, p. 91-111, 2005.

OLIVEIRA, L. R. C. de. Direito legal e insulto moral: dilemas de cidadania no Brasil, Quebec e EUA. Rio de Janeiro: Relume Dumará: Núcleo de Antropologia Política, 2002.

SANJINÉS, I. Lecciones aprendidas sobre consulta previa. La Paz: CEJIS, 2010 . 
SCARAMUZZI, I. A resistência dos quilombolas de Oriximiná à mineração. In: NOBRE, M. (Org.). Violência e desigualdade no Brasil. São Paulo: Sempreviva Organização Feminista, 2017. p. 67-82.

SHIRAISHI NETO, J. A particularização o universal: povos e comunidades tradicionais face às declarações e convenções internacionais. In: SHIRAISHI NETO, J. (Org.). Direito dos povos e das comunidades tradicionais no Brasil: declarações, convenções internacionais e dispositivos jurídicos definidores de uma política nacional. Manaus: UEA, 2007. p. 25-52.

SILVA, L. A. L. da. Parecer sobre a implementação da consulta prévia na América Latina. In: SOUZA FILHO, C. F. M.; ROSSITO, F. D. (Orgs.). Estudos sobre o cadastro ambiental rural (CAR) e consulta prévia: povos tradicionais. Curitiba: Letra da Lei, 2016. p. 71.

SIMBAÑA, F. Consulta previa y democracia em El Ecuador. Revista Latinoamericana de Comunicación-Chasqui, Quito, n. 120, p. 4-8, dec. 2012. TURNER, V. Schismand continuity in an African society. Manchester: Manchester University Press, 1996 [1957].

Dramas, campos e metáforas: ação simbólica na sociedade humana. Niterói: Editora da Universidade Federal Fluminense, 2008.

VELOZ, C. R. A Convenção 169, seu conteúdo e alcance. In: CONVENÇÃO 169 DA OIT SOBRE POVOS INDÍGENAS E TRIBAIS: oportunidades e desafios para sua implementação no Brasil. São Paulo. Anais... São Paulo: Instituto Socioambiental, 2009. p. 59-65.

WANDERLEY, L. J. de M. Conflitos e movimentos sociais populares em área de mineração na Amazônia brasileira. Rio de Janeiro: UFRJ/PPGG, 2008. 